\title{
Efeito do Nível de Energia da Dieta e da Exposição Prévia ao Calor sobre a Respiração Mitocondrial do Músculo Cardíaco de Frangos de Corte ${ }^{1}$
}

\author{
Marcos Macari², Renato Luís Furlan ${ }^{3}$, José Roberto Guerreiro ${ }^{4}$, Euclides Roberto Secato ${ }^{4}$
}

\begin{abstract}
RESUMO - Este trabalho foi realizado com o objetivo de avaliar o efeito do nível de energia da dieta, da exposição prévia ao calor e do sexo de frangos de corte sobre a atividade respiratória das mitocôndrias do músculo cardíaco de fragos de corte. Foram usados frangos Hubbard, de ambos os sexos, alimentados com ração contendo 2900 ou $3200 \mathrm{kcal}$ de EM/kg e criados em câmara climática. Os frangos foram estressados por calor $\left(35^{\circ} \mathrm{C} / 4 \mathrm{~h}\right)$ no $1^{\circ}, 21^{\circ}$ e $42^{\circ}$ dia de idade. A atividade respiratória das mitocôndrias do músculo cardíaco foi avaliada por intermédio de oxígrafo Gilson modelo 5/6, utilizando-se alfa-ceto-glutarato como substrato e ADP (adenosina-di-fosfato) para estimular a atividade respiratória. Não houve efeito do nível de energia da ração e de estresse calórico prévio sobre a atividade respiratória mitocondrial do músculo cardíaco. Contudo, as fêmeas apresentaram maior atividade respiratória que os machos. Em razão da menor capacidade oxidativa das fibras musculares do coração dos frangos machos, estes podem ser mais susceptíveis a problemas cardíacos que as fêmeas.
\end{abstract}

Palavras-chave: frangos de corte, respiração mitocôndrial, músculo cardíaco, energia da dieta

\section{Effect of Dietary Energy Level and Previous Heat Exposure on the Respiratory Activity of the Mitochondria from Cardiac Muscle of Broiler Chickens}

\begin{abstract}
This work was conducted aiming to evaluate the effect of dietary energy level and the previous heat exposure on the respiratory activity of the mitochondria from the cardiac muscle of broiler chickens. It was used broiler chickens (Hubbard) from both sexes and fed with diet containing $2900 \mathrm{kcal} \mathrm{ME} / \mathrm{kg}$ or $3200 \mathrm{kcal} \mathrm{ME} / \mathrm{kg}$. The birds were heat stressed $\left(35^{\circ} \mathrm{C} / 4 \mathrm{~h}\right) \mathrm{in}$ the $1^{\mathrm{st}}, 21^{\mathrm{st}}$ and $42^{\text {nd }}$ days of age. The respiratory activity of mitochondria from cardiac muscle was evaluated in a Gilson oxygraph, model 5/6, by using alpha-ceto-glutaric as substrate and the ADP (adenosine-di-phosphate) to stimulate the respiratory activity. There was not effect of dietary energy level and previous heat exposure on the respiratory activity of the mitochondria from cardiac muscle. However, the females presented higher respiratory activity than males. By reason of the low oxidative capability of the heart muscle fiber of the male broiler chickens, these could be more sensitive to cardiac disease than females.
\end{abstract}

Key Words: broiler chickens, mitochondria respiratory activity, cardiac muscle, dietary energy

\section{Introdução}

Estudos mostram que o exercício é bom modelo para o estudo das alterações mitocondriais em músculo estriado. HOLLOSZY (1967) relatou que a quantidade de mitocôndrias no músculo pode ser aumentada em função da intensidade do exercício, proporcionando, dessa forma, maior capacidade oxidativa para este tecido. Segundo BICUDO (1990), o treinamento físico prolongado permite a mamíferos ter seu potencial aumentado 1,5 vez, o que poderá acarretar variações nos músculos cardíacos e respiratórios envolvidos nos exercícios. BRACKENBURY e WILLIAMSON (1989) também mostraram que o exercício físico é capaz de aumentar a capacidade oxidativa do músculo estriado de aves, de forma semelhante à descrita nos mamíferos.

A interação do animal com o meio ambiente parece ser importante variável que influi na atividade mitocondrial em músculos estriados. DEPOCAS (1966) mostrou que ratos aclimatados ao frio apresentaram maior quantidade de mitocôndrias, bem como maior atividade das enzimas respiratórias. Em contrapartida, a exposição a ambientes quentes estaria associada a decréscimo no número de mitocôndrias e na atividade das enzimas (SWAROOP E RAMASARMA, 1982). Estes achados foram corroborados por CHEAH et al. (1985), os quais mostraram que, em suínos mantidos à temperatura ambiente de $10^{\circ} \mathrm{C}$, a concentração de enzimas e

\footnotetext{
${ }_{1}^{1}$ Projeto financiado pela FAPESP (Proc. 92/3076-0) e pelo CNPq (Proc. 300698/83-6).

2 Professor Titular, Departamento de Morfologia e Fisiologia Animal, FCAV/UNESP, Rodovia Carlos Tonanni, Km 5 - 14870-000, Jaboticabal - São Paulo- Brasil. FONE: (016) 323-2500; FAX: (016) 322-4275; E-mail macari@fcav.unesp.br

${ }^{3}$ Professor Assistente Doutor, Departamento de Morfologia e Fisiologia Animal, FCAV/UNESP.

${ }^{4}$ Técnico do Laboratório de Morfologia e Fisiologia Animal, FCAV/UNESP.
} 
proteína mitocondrial no músculo estriado (Longissimus dorsi) aumentou, quando comparada com a de suínos mantidos a $35^{\circ} \mathrm{C}$.

Investigações sobre a característica funcional das mitocôndrias têm mostrado que os lipídeos podem influir na função mitocondrial. CLANDININ (1978) verificou que ratos alimentados com dieta contendo ácidos graxos de cadeia longa apresentaram declínio na oxidação de substratos e decréscimo na síntese de ATP nas mitocôndrias do coração. Em aves, foi demonstrado que a baixa eficiência energética de uma dieta contendo alto nível de óleo de canola era atribuída ao desacoplamento da fosforilação oxidativa (RENNER et al., 1979).

Considerando que a atividade muscular cardíaca em frangos de corte pode ser influenciada de acordo com a condição ambiental de criação, este trabalho foi desenvolvido com o objetivo de pesquisar o efeito do estresse prévio pelo calor sobre a atividade respiratória de mitocôndrias extraídas de músculo cardíaco de frangos de corte, machos e fêmeas, arraçoados com diferentes níveis de energia metabolizável na ração.

\section{Material e Métodos}

Frangos de corte, machos e fêmeas, da linhagem Hubbard, sexados no incubatório e criados até 42 dias de idade, foram utilizados neste experimento. As aves foram alojadas em câmara climática, em condições de termoneutralidade, de acordo com a idade. Os pintos foram vacinados (Doença de Marek, Bouba aviária, Doença de Gumboro e Doença de NewCastle) de acordo com as recomendações profiláticas.

As rações usadas neste experimento, à base de milho e farelo de soja, foram formuladas de acordo com ROSTAGNO et al. (1983), com níveis de energia de 2900 e $3200 \mathrm{kcal}$ de energia metabolizável (EM) $/ \mathrm{kg}$ e $22 \%$ proteína bruta para a fase inicial (1 a 21 dias de idade) e $20 \%$ de proteína bruta para a fase de crescimento ( 22 a 42 dias de idade).

O estresse pelo calor consistiu em transferir os frangos da condição ambiental de termoneutralidade para a câmara climática com temperatura de $35 \pm 1^{\circ} \mathrm{C}$; os animais permaneceram a esta temperatura durante 4 horas. Os animais foram estressados nas idades de 1,21 e 42 dias e sacrificados para avaliação da atividade respiratória mitocôndrial cardíaca somente aos 42 dias de idade e após 4 horas de estresse, quando as mitocôndrias foram extraídas do músculo cardíaco.

O músculo cardíaco (coração) retirado foi colocado em meio de homogeneização e homogeneizado em "Turrax" em três séries de 30 segundos de duração, com intervalo de descanso de 1 minuto. Durante todo o processo, o material foi mantido gelado. A extração e o isolamento foram realizados por centrifugação diferencial após a ruptura da membrana celular. O pellete mitocondrial foi suspenso em sacarose $(250 \mathrm{mM})$ antes de ser utilizado.

O consumo de oxigênio das mitocôndrias foi determinado por intermédio de eletrodo de oxigênio tipo Clark, conectado a oxígrafo Gilson modelo 5/6. Foi utilizado como substrato o alfa-ceto-glutarato, sendo a respiração mitocondrial estimulada por meio de ADP (adenosina-di-fosfato). A concentração de proteína nas mitocôndrias foi determinada pelo método de HARTREE (1972), com o objetivo de proceder às correções dos resultados obtidos.

O delineamento experimental utilizado foi o inteiramente casualizado, segundo esquema fatorial $2 \times 2 \times 2$, com fatores: sexo (macho e fêmea), nível de energia (2900 e $3200 \mathrm{kcal} \mathrm{EM/kg)} \mathrm{e} \mathrm{estresse} \mathrm{calórico}$ (estressados e não-estressados), com cinco repetições por tratamento, sendo cada parcela constituída por uma ave. As análises de variância do presente estudo foram realizadas pelo procedimento GLM do SAS (Statistical Analysis System, 1985).

\section{Resultados e Discussão}

O efeito do estresse calórico e do nível de energia da ração sobre a atividade respiratória de mitocôndrias do músculo cardíaco de frangos de corte, machos e fêmeas, são mostrados na Tabela 1. O estresse calórico não teve efeito sobre a atividade respiratória das mitocôndrias do músculo cardíaco. ARJONA et al. $(1988,1990)$ relataram que a exposição prévia de frangos de corte ao calor aos 5 dias de idade reduziu o índice de mortalidade das aves, quando submetidas ao estresse pelo calor aos 42 dias. Recentemente, YAHAV e HURWITZ (1996) também mostraram que a termotolerância pode ser induzida pela exposição prévia ao calor, com possível participação das proteínas de estresse neste mecanismo (proteínas de choque térmico, Hsp). GABRIEL et al. (1996) relataram que a síntese destas proteínas de estresse no fígado, bem como de seu mRNA (RNA mensageiro), em frangos de corte, eram dependentes do tempo e da magnitude do estresse. No entanto, YAHAV et al. (1997) relataram que a síntese destas proteínas no coração e pulmão de frangos de corte apresentaram correlação com a magnitude da resposta hipertérmica, mas que pareceu não fazer parte dos mecanismos de 
120 Rev. bras. zootec.

Tabela 1 - Efeito do estresse calórico prévio, sexo e nível de energia da dieta sobre a atividade respiratória de mitocôndrias extraídas do coração de frangos de corte

Table 1 - Effect of previous heat stress, sex and dietary energy level on cardiac mitochondrial respiratory activity from broiler chickens

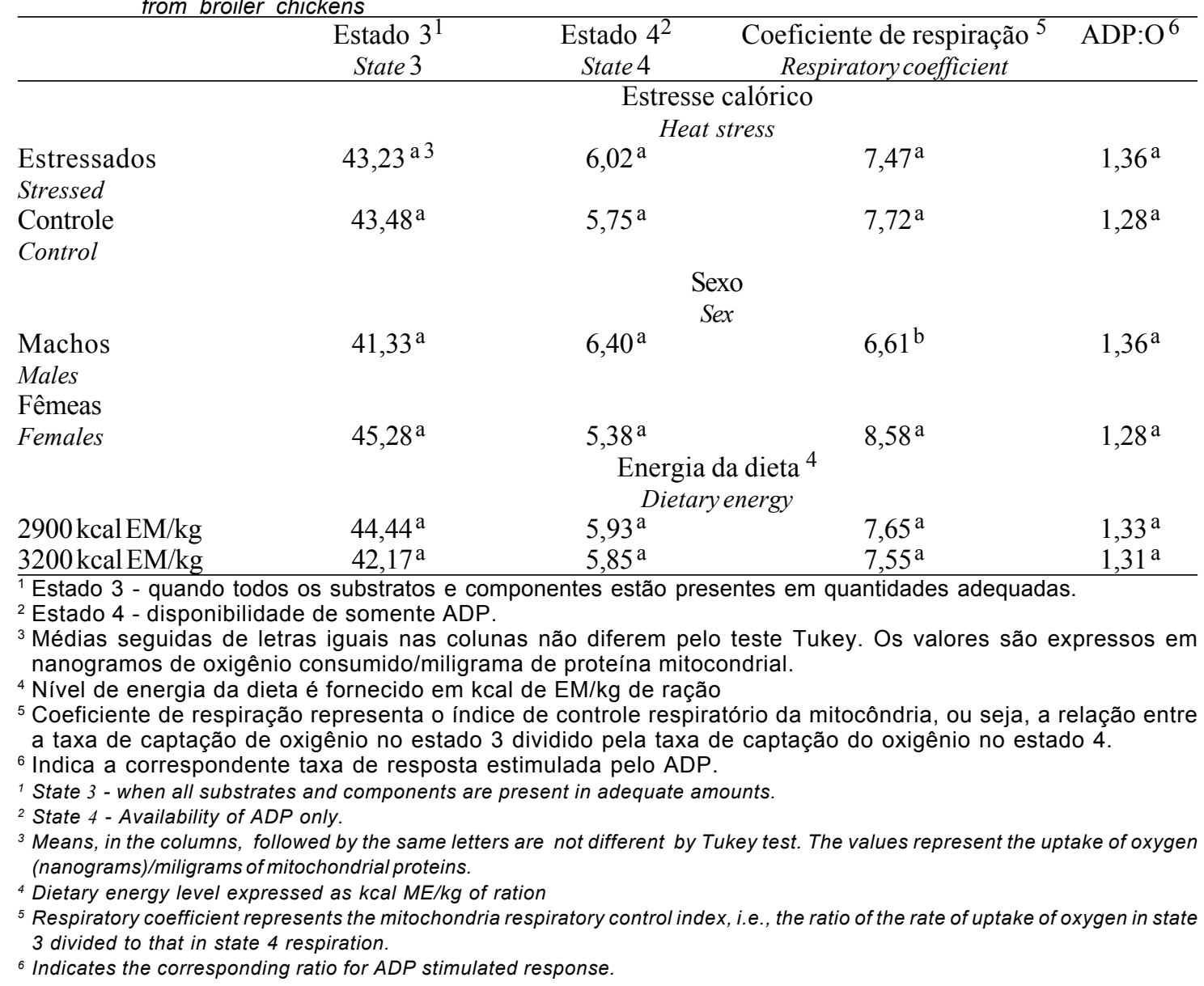

termotolerância de longo-prazo induzidos, quando da exposição prévia ao calor. Assim, os resultados deste experimento sugerem que a atividade respiratória das mitocôndrias do músculo cardíaco não sofre influência do estresse calórico e que possíveis melhorias na termotolerância de frangos previamente estressados não parece estar associadas à maior capacidade oxidativa das fibras musculares do coração.

Não foi observado efeito do nível de energia da ração sobre a atividade respiratória das mitocôndrias do coração dos frangos de corte. CHEAH et al. (1985) mostraram que suínos submetidos a nível de energia muito baixo apresentaram alterações na atividade respiratória mitocondrial, as quais foram acentuadas quando estes animais foram expostos ao frio. Foi sugerido que o efeito da energia da ração é fator determinante de alteração da atividade mitocondrial do músculo cardíaco, quando os animais são criados em baixas temperaturas ambientais. Assim, os níveis de energia das rações utilizadas neste estudo e em altas temperaturas ambientais parece não interferir na atividade mitocondrial.

Com relação ao sexo, constatou-se que os frangos machos apresentaram menor $(\mathrm{P}<0,05)$ atividade respiratória das mitocôndrias do coração que as fêmeas, evidenciando menor capacidade oxidativa das fibras musculares dos machos. Este fato pressupõe que a atividade cardíaca do macho, do ponto de vista da atividade mitocondrial, é menor que na fêmea, sugerindo maior sensibilidade a problemas cardiovasculares. A resposta mitocondrial com relação à hereditariedade tem sido avaliada. Neste sentido, MUKHERJEE et al. (1970) observaram que o consumo de oxigênio diferiu entre as raças White Leghorn e White Rock. BROWN et al. (1986), estudando matrizes leves e pesadas, encontraram maior atividade mitocondrial nas matrizes pesadas. Estas observações permitem inferir que as diferenças encontradas no presente experimento também estejam associadas às características genotípicas e hereditárias de machos e fêmeas. 


\section{Conclusões}

A capacidade oxidativa das fibras musculares dos frangos de corte machos foi menor que a das fêmeas, sugerindo que machos podem ser mais susceptíveis a problemas cardíacos que as fêmeas.

A exposição prévia e aguda ao estresse calórico ( $35^{\circ} \mathrm{C} / 4$ horas) e o nível energético da ração (2900 e $3200 \mathrm{kcal} \mathrm{EM} / \mathrm{kg}$ ) não influenciaram a respiração mitocondrial do músculo cardíaco dos frangos de corte.

\section{Referências Bibliográficas}

ARJONA, A.A., DENBOW, D.M., WEAVER, JR. W.D. 1988. Effect of heat stress early in life on mortality of broilers exposed to high environmental temperatures just prior to marketing. Poult. Sci., 67(2):226-231.

ARJONA, A.A., DENBOW, D.M., WEAVER, JR., W.D. 1990. Neonatally induced thermotolerance: physiological responses. Comparative Biochemistry and Physiology, 95(3):393-399.

BICUDO, J.E.P.W. 1990. Transporte de oxigênio: estratégias e limites. Ciência Hoje, Rio de Janeiro, 12(69):30-37.

BRACKENBURY, J.H., WILLIAMSON, A.D.B. 1989. Treadmill exercise training increases the oxidative capacity of chickens iliotibialis muscle. Poult. Sci., 68(4):577-581.

BROWN, D.R., DENISE, S.K., McDANIEL, R.G. 1986. Hepatic mitochondrial activity in two breeds of chickens. Poult. Sci., 65(4):613-615.

CHEAH, K.S., DAUNCEY, M.J., CHEACH, A.M. AND INGRAM, D.L. 1985. Influence of environmental temperature and energy intake on porcine skeletal muscle mitochondria. Comparative Biochemistry and Physiology, 82(2):287-292.

CLANDININ, M.T. 1978. The role of dietary long chain fatts acids in mitochondrial structure and function. Effects on rat cardiac mitochondrial respiration. J. Nut., 108(2):273-281.

DEPOCAS, F. 1966. Concentration and turnover of cytochrome $\mathrm{C}$ in skeletal muscles of warm and cold acclimated rats. Can. J. Phys. Pharm., 44(8):875-80.

GABRIEL, J.E., FERRO, J.A., STEFANI, R.M.P. et al. 1996. Effect of acute heat stress on heat shock protein 70 messenger RNA and on heat shock protein expression in the liver of broilers. Br. Poult. Sci., 37(2):435-441.

HARTREE, E.F. 1972. Determination of protein: a modification of the Lowry method that gives a linear photometry response. Anal. Bioch.,48(2):422-427.

HOLLOSZY, J.O. 1967. Biochemical adaptations in muscle. $J$. Biol. Chem., 242(11):2278-2282.

MUKHERJEE, T.K., STEVENS, R.W.C., HOOGENDOORN, M.P. 1970. Oxygen uptake of mitochondrial isolates from two breeds of chickens and their F1 cross. Poult. Sci, 49(4):1130-1131.

RENNER, R., INNIS, S.M., CLANDININ, M.T. 1979. Effects of high and low erucic acid rapeseed oils on energy metabolism and mitochondrial function of the chick. J. Nut., 109(3):378-387.

ROSTAGNO, H.S., SILVA, D.S., COSTA, P.M.A. et al. 1983. Composição de alimentos e exigências nutricionais de aves e suínos (Tabelas Brasileiras). Viçosa, MG: Impr.Univ., 61p.

SAS Institute, SAS (Statistical Analysis System). Users guide. SAS Institute Inc., Cary, NC. 1985.

SWAROOP, A., RAMASARMA, P. 1982. Changes in mitochondrial oxidative metabolism under conditions of heat stress. Ind. J. Bioch. Biophy., 19(2):382-387.

YAHAV, S., HURWITZ, S. 1996. Effects of diurnally cycling versus constant temperatures on chicken growth and food intake. Br. Poult. Sci., 37(1):43-54.

YAHAV, S.S., SHAMAY, A., HOREV, G. et al. 1997. Effect of acquisition of improved thermotolerance on the induction of heat shock proteins in broilers chickens. Poult. Sci., 74(10):1428-1434.

Recebido em: $13 / 02 / 98$

Aceito em: 21/08/98 